\title{
Interictal Epileptiform Discharges Might Be More Likely During Particular Phases of Brain Activity
}

\author{
David F. Abbott ${ }^{1,2 *}$ \\ ${ }^{1}$ The Florey Institute of Neuroscience and Mental Health, Austin Hospital, Melbourne, VIC, Australia, ${ }^{2}$ The University of \\ Melbourne, Melbourne, VIC, Australia
}

Keywords: epilepsy, functional magnetic resonance imaging, fMRI, functional connectivity, default mode network, dynamic, temporal lobe epilepsy, genetic generalized epilepsy

\section{A commentary on}

Study on the relationships between intrinsic functional connectivity of the default mode network and transient epileptic activity

by Lopes R, Moeller F, Besson P, Ogez F, Szurhaj W, Leclerc X, et al. Front Neurol (2014) 5:201. doi: 10.3389/fneur.2014.00201

Many epilepsy patients exhibit intermittent abnormal brain activity, evident as abnormal electrical events on electroencephalography (EEG), at times when they are not having a seizure. Despite the ease with which these so-called interictal epileptiform discharges (IEDs) can be detected, and a reasonable understanding of the physiological processes occurring during the IED (1), the effect of IEDs on brain function and the nature of their association with seizures remains unclear.

Several recent studies of the potential effects of IEDs on brain function have examined activity within the default mode network [DMN; (2)], a major distributed functional network of the healthy brain typically associated with introspective tasks such as autobiographical memories, internal rumination, or random episodic silent thinking [REST; (3)]. Major nodes of the DMN include posterior cingulate/retrosplenial cortex, medial prefrontal cortex, and the inferior parietal lobule

OPEN ACCESS

Edited by:

Jorge Asconape, Loyola University, USA

Reviewed by: Patricia Braga, Instituto de Neurología, Uruguay

*Correspondence: David F. Abbott d.abbott@brain.org.au

Received: 12 September 2015 Accepted: 16 November 2015 Published: 04 December 2015

Citation:

Abbott DF (2015) Interictal Epileptiform Discharges Might Be More Likely During Particular Phases of Brain Activity.

Front. Neurol. 6:253. doi: 10.3389/fneur.2015.00253 (4). It has been postulated that abnormal activity in the DMN may be a causative factor in loss of awareness during seizures (5). Studies of IEDs have demonstrated a temporal association between the discharges and activity changes in nodes of the DMN. For example, deactivation of DMN is observed in several generalized and focal epilepsies (6-10), and activation in DMN is associated with some IED types (11). However, a causal link has not been definitively established: IEDs might cause DMN changes, or there may be certain, perhaps normal, functional states of the brain that are more permissive than others to the occurrence of epileptiform activity (12-15).

Lopes et al. have now addressed this issue by measuring the intrinsic functional connectivity of the DMN in patients immediately before, during and after epileptiform activity, and comparing the connectivity in these periods with a baseline well away from the epileptiform activity (16). They utilized sliding-window dynamic functional connectivity, a multivariate approach that assesses correlations in activity between brain regions over relatively short timespans (typically of the order of tens of seconds) (17). Lopes et al. studied both idiopathic generalized epilepsy (IGE) [i.e., genetic generalized epilepsy (GGE) (18)] and temporal lobe epilepsy (TLE).

An interesting observation of this study is an overall increase in intrinsic connectivity in portions of the DMN several seconds prior to the onset of IEDs in both GGE and TLE. That this increase is observed prior to the IED suggests it is not the IED causing the change. The authors suggest that the "DMN connectivity may facilitate IED generation." The fact that the increase in DMN activity in GGE patients occurred bilaterally, while in TLE patients, it occurred mainly in nodes ipsilateral to the affected temporal lobe, is consistent with the authors' hypothesis. However, while the hypothesis is plausible, there exist other possible explanations. For example, EEG spikes become 
visible only when a large area of cortex is synchronously active (19). Abnormal activity not visible on EEG may therefore be present prior to the IED, building to a stage that ultimately culminates in the observed IED. In the present case, pre-IED abnormal activity might have caused both the observed DMN connectivity changes and the IED. Nevertheless, it seems reasonable to conclude at least that the IEDs observed on EEG did not cause the preceding DMN changes in the studied patients.

Although intriguing, results at this stage are from small subject numbers (six GGE and six TLE patients), due largely to the difficulty in collecting suitable data (studies with sufficient interictal events spaced far enough apart). The results can therefore only be considered pilot in nature. The study points the way forward for larger studies to investigate these issues. One possibility in this regard is greater sharing of data across centers. Lopes et al. themselves obtained data across two centers; sharing of data across a greater number of centers may yield a more substantial cohort.

Independently of Lopes et al., Faizo et al. recently studied functional connectivity between hippocampi immediately prior to IEDs in a group of 15 mesial TLE patients (20). They observed functional connectivity decrease prior to the IED onset. Taken

\section{REFERENCES}

1. McCormick DA, Contreras D. On the cellular and network bases of epileptic seizures. Annu Rev Physiol (2001) 63:815-46. doi:10.1146/annurev.physiol.63. 1.815

2. Raichle ME, MacLeod AM, Snyder AZ, Powers WJ, Gusnard DA, Shulman GL. A default mode of brain function. Proc Natl Acad Sci U S A (2001) 98(2):676-82. doi:10.1073/pnas.98.2.676

3. Andreasen NC, O'Leary DS, Cizadlo T, Arndt S, Rezai K, Watkins GL, et al. Remembering the past: two facets of episodic memory explored with positron emission tomography. Am J Psychiatry (1995) 152(11):1576-85. doi:10.1176/ ajp.152.11.1576

4. Buckner RL, Andrews-Hanna JR, Schacter DL. The brain's default network: anatomy, function, and relevance to disease. Ann N Y Acad Sci (2008) 1124:1-38. doi:10.1196/annals.1440.011

5. Danielson NB, Guo JN, Blumenfeld H. The default mode network and altered consciousness in epilepsy. Behav Neurol (2011) 24(1):55-65. doi:10.3233/BEN2011-0310

6. Archer JS, Abbott DF, Waites AB, Jackson GD. fMRI "deactivation" of the posterior cingulate during generalized spike and wave. Neuroimage (2003) 20(4):1915-22. doi:10.1016/S1053-8119(03)00294-5

7. Salek-Haddadi A, Diehl B, Hamandi K, Merschhemke M, Liston A, Friston K, et al. Hemodynamic correlates of epileptiform discharges: an EEG-fMRI study of 63 patients with focal epilepsy. Brain Res (2006) 1088(1):148-66. doi:10.1016/ j.brainres.2006.02.098

8. Laufs H, Hamandi K, Salek-Haddadi A, Kleinschmidt AK, Duncan JS, Lemieux L. Temporal lobe interictal epileptic discharges affect cerebral activity in "default mode" brain regions. Hum Brain Mapp (2007) 28(10):1023-32. doi:10.1002/ hbm. 20323

9. Fahoum F, Lopes R, Pittau F, Dubeau F, Gotman J. Widespread epileptic networks in focal epilepsies: EEG-fMRI study. Epilepsia (2012) 53(9):1618-27. doi:10.1111/j.1528-1167.2012.03533.x

10. Fahoum F, Zelmann R, Tyvaert L, Dubeau F, Gotman J. Epileptic discharges affect the default mode network - fMRI and intracerebral EEG evidence. PLoS One (2013) 8(6):e68038. doi:10.1371/journal.pone.0068038

11. Archer JS, Warren AE, Stagnitti MR, Masterton RA, Abbott DF, Jackson GD. Lennox-Gastaut syndrome and phenotype: secondary network epilepsies. Epilepsia (2014) 55(8):1245-54. doi:10.1111/epi.12682

12. Masterton RAJ, Harvey AS, Archer JS, Lillywhite LM, Abbott DF, Scheffer IE, et al. Focal epileptiform spikes do not show a canonical BOLD together with the observations of Lopes et al., this suggests there may be systematic complex alterations in functional connectivity, including both increases and decreases, between different brain nodes prior to IEDs.

The work of Lopes et al. and others demonstrate the value of neuroimaging studies of the peri-event dynamics of IEDs, justifying increased effort in this research domain. Understanding the nature of interactions between "normal" and "abnormal" brain activity may provide new clues as to the nature of various epilepsy phenotypes, and potentially novel avenues for treatment. In addition to larger studies of GGE and TLE, it would be useful if future studies examined additional brain networks, and other epilepsy syndromes.

\section{FUNDING}

DA gratefully acknowledges fellowship funding from the Australian National Imaging Facility, and support from the National Health and Medical Research Council (NHMRC) and the Operational Infrastructure Support Program of the State Government of Victoria, Australia.

response in patients with benign rolandic epilepsy (BECTS). Neuroimage (2010) 51(1):252-60. doi:10.1016/j.neuroimage.2010.01.109

13. Vaudano AE, Laufs H, Kiebel SJ, Carmichael DW, Hamandi K, Guye M, et al. Causal hierarchy within the thalamo-cortical network in spike and wave discharges. PLoS One (2009) 4(8):e6475. doi:10.1371/journal.pone.0006475

14. Carney PW, Jackson GD. Insights into the mechanisms of absence seizure generation provided by EEG with functional MRI. Front Neurol (2014) 5:162. doi:10.3389/fneur.2014.00162

15. Archer JS, Warren AE, Jackson GD, Abbott DF. Conceptualizing lennox-gastaut syndrome as a secondary network epilepsy. Front Neurol (2014) 5:225. doi:10. 3389/fneur.2014.00225

16. Lopes R, Moeller F, Besson P, Ogez F, Szurhaj W, Leclerc X, et al. Study on the relationships between intrinsic functional connectivity of the default mode network and transient epileptic activity. Front Neurol (2014) 5:201. doi:10.3389/ fneur.2014.00201

17. Hutchison RM, Womelsdorf T, Allen EA, Bandettini PA, Calhoun VD, Corbetta $\mathrm{M}$, et al. Dynamic functional connectivity: promise, issues, and interpretations. Neuroimage (2013) 80:360-78. doi:10.1016/j.neuroimage.2013.05.079

18. Berg AT, Berkovic SF, Brodie MJ, Buchhalter J, Cross JH, van Emde Boas W, et al. Revised terminology and concepts for organization of seizures and epilepsies: report of the ILAE commission on classification and terminology, 2005-2009. Epilepsia (2010) 51(4):676-85. doi:10.1111/j.1528-1167.2010. 02522.x

19. Tao JX, Ray A, Hawes-Ebersole S, Ebersole JS. Intracranial EEG substrates of scalp EEG interictal spikes. Epilepsia (2005) 46(5):669-76. doi:10.1111/j.15281167.2005.11404.x

20. Faizo NL, Burianova H, Gray M, Hocking J, Galloway G, Reutens D. Identification of pre-spike network in patients with mesial temporal lobe epilepsy. Front Neurol (2014) 5:222. doi:10.3389/fneur.2014.00222

Conflict of Interest Statement: The author declares that the research was conducted in the absence of any commercial or financial relationships that could be construed as a potential conflict of interest.

Copyright (C) 2015 Abbott. This is an open-access article distributed under the terms of the Creative Commons Attribution License (CC BY). The use, distribution or reproduction in other forums is permitted, provided the original author(s) or licensor are credited and that the original publication in this journal is cited, in accordance with accepted academic practice. No use, distribution or reproduction is permitted which does not comply with these terms. 